\title{
Reply to the Letter to Editor by Lacout and colleagues: Chloroquine and Hydroxychloroquine for the Treatment of COVID-19: a Systematic Review and Meta-analysis
}

J Gen Intern Med 36(8):2468-9

DOI: $10.1007 / \mathrm{s} 11606-021-06722-8$

(c) Society of General Internal Medicine 2021

$\mathrm{W}$ e thank Lacout and colleagues for their comments on our systematic review and meta-analysis. ${ }^{1}$ The authors propose that early use (e.g., $\leq 3$ days since symptom onset) of hydroxychloroquine (HCQ) may be associated with better outcomes in patients with COVID-19. However, the available evidence including 3 recent randomized controlled trials (RCTs) has failed to show benefit of HCQ even in patients with shorter symptom duration and milder illness at baseline and those who were not hospitalized, or when used for postexposure prophylaxis.

Boulware et al. $^{2}$ administered HCQ or placebo to participants within 4 days of exposure. The incidence of symptomatic illness did not differ significantly between HCQ (49 of 414 [11.8\%]) and placebo (58 of 407 [14.3\%]; absolute difference -2.4 , 95\% confidence interval, -7.0 to $2.2 ; P=0.35)$.

In another $\mathrm{RCT}^{3}$ there was no significant difference in clinical status at 14 days between the HCQ and placebo in prespecified subgroups by baseline illness severity or duration of symptoms: aOR for recovery in patients with symptoms 0 to 3 days was 0.95 (95\% CI 0.52 to 1.73 ) and for 4 to 6 days 1.11 (95\% CI 0.63 to 1.94$)$.

In yet another $\mathrm{RCT},{ }^{4}$ no benefit of $\mathrm{HCQ}$ was seen in mild to moderate COVID-19 patients. Of the 59 patients who were enrolled within 3 days of onset, the number of patients who were at home at day 14 was 6/16 (38\%) in the HCQ-plusazithromycin group, 10/19 (53\%) in the HCQ-alone group, and $14 / 24(58 \%)$ in the control group.

The preprint systematic review cited by the authors ${ }^{5}$ has pooled the results across different outcomes (death, hospitalization, and infection). Meta-analysis should only be considered when a group of studies is sufficiently homo-

Received December 19, 2020

Accepted March 14, 2021

Published online April 26, 2021 geneous in terms of participants, interventions, and outcomes to provide a meaningful summary. Also, one of the included trials studied the effect of HCQ as pre-exposure prophylaxis, a clinically distinct use from what the other trials studied. For these reasons, this meta-analysis might have yielded an erroneous pooled estimate and confidence interval.

Regarding cardiotoxicity, both chloroquine and HCQ interfere with ventricular repolarization, leading to prolongation of the QTc interval and an increased risk of torsades de pointes. Studies involving volunteers found mean increases in QTc of $6.1 \mathrm{~ms}$ after a dose of $600 \mathrm{mg}$ and $28 \mathrm{~ms}$ after $1200 \mathrm{mg}$.

Thus, the available literature does not favor HCQ in the treatment of COVID-19 even if used early and in milder cases.

Manya Prasad, $\mathrm{MD}^{1}$

Arunmozhimaran Elavarasi, $\mathrm{MD}^{2}$

Pramod Garg, $M D^{3}$

${ }^{1}$ Department of Community Medicine, NDMC Medical College,

New Delhi, India

${ }^{2}$ Departments of Neurology, All India Institute of Medical Sciences,

New Delhi, India

${ }^{3}$ Gastroenterology and Human Nutrition Unit, All India Institute of Medical Sciences,

New Delhi, India

Corresponding Author: Pramod Garg, MD; Gastroenterology and Human Nutrition Unit, All India Institute of Medical Sciences, New Delhi, India (e-mail: pkgarg@aiims.ac.in).

\section{REFERENCES}

1. Elavarasi A, Prasad M, Seth T, Sahoo RK, Madan K, Nischal N, et al. Chloroquine and Hydroxychloroquine for the Treatment of COVID-19: a Systematic Review and Meta-analysis. J Gen Intern Med. 2020 Nov;35(11):3308-3314. doi: https://doi.org/10.1007/s11606-020-06146w. Epub 2020 Sep 3.

2. Boulware DR, Pullen MF, Bangdiwala AS, Pastick KA, Lofgren SM, Okafor EC, et al. A randomized trial of hydroxychloroquine as postexposure prophylaxis for Covid-19. New England Journal of Medicine. 2020 Aug 6;383(6):517-25. 
3. Self WH, Semler MW, Leither LM, Casey JD, Angus DC, Brower RG, et al. Effect of hydroxychloroquine on clinical status at 14 days in hospitalized patients with COVID-19: a randomized clinical trial. JAMA. 2020 Dec 1;324(21):2165-76.

4. Cavalcanti AB, Zampieri FG, Rosa RG, Azevedo LCP, Veiga VC, Avezum A, et al. Hydroxychloroquine with or without azithromycin in mild-tomoderate Covid-19. New England Journal of Medicine. 2020 Nov 19;383(21):2041-52.
5. Ladapo JA, McKinnon JE, McCullough PA, Risch H. Randomized controlled trials of early ambulatory hydroxychloroquine in the prevention of COVID-19 infection, hospitalization, and death: meta-analysis. medRxiv. 2020 Jan 1;2020.09.30.20204693.

Publisher's Note: Springer Nature remains neutral with regard to jurisdictional claims in published maps and institutional affiliations. 